\title{
Erratum to: Dynamic evaluation of renal resistive index in normoalbuminuric patients with newly diagnosed hypertension or type 2 diabetes
}

\author{
R. M. Bruno • E. Daghini $\cdot$ L. Landini $\cdot$ D. Versari $\cdot$ \\ A. Salvati • E. Santini • I. Di Paco • A. Magagna • \\ S. Taddei $\cdot$ L. Ghiadoni $•$ A. Solini
}

Published online: 6 July 2011

(C) Springer-Verlag 2011

\section{Erratum to: Diabetologia \\ DOI 10.1007/s00125-011-2148-y}

The first sentence of the second paragraph of the Results should have read: 'RI values were significantly higher in participants with type 2 diabetes compared with $\mathrm{EH}$ and control participants $(0.65 \pm 0.06,0.59 \pm 0.05$ and $0.58 \pm 0.05$ respectively), while those participants with $\mathrm{EH}$ showed values superimposable to controls (Fig. 2a)' to match the data presented in Fig. 2a.

The online version of the original article can be found at http://dx.doi. org/10.1007/s00125-011-2148-y.

R. M. Bruno · E. Daghini $\cdot$ L. Landini $\cdot$ D. Versari · A. Salvati ·

E. Santini $\cdot$ I. Di Paco $\cdot$ A. Magagna $\cdot$ S. Taddei $\cdot$

L. Ghiadoni $(\bowtie) \cdot$ A. Solini

Department of Internal Medicine, University of Pisa,

Via Roma 67,

56100 Pisa, Italy

e-mail: 1.ghiadoni@med.unipi.it 